\title{
Malignancy Rate in Thyroid Nodules with Atypia or Follicular Lesion of Undetermined Significance
}

\author{
Hamdan Ahmed Pasha ${ }^{1}$ Rahim Dhanani ${ }^{1} \quad$ Ainulakbar Mughal $^{1} \quad$ Kaleem S. Ahmed $^{1}$ Anwar Suhail ${ }^{1}$ \\ ${ }^{1}$ Department of Surgery, Section of Otolaryngology/Head and Neck \\ Surgery, Aga Khan University, Karachi, Pakistan \\ Int Arch Otorhinolaryngol 2020;24:e221-e226. \\ Address for correspondence Dr. Hamdan Pasha, MBBS, Department \\ of Surgery, Section of Otolaryngology/Head and Neck Surgery, Aga \\ Khan University, National Stadium Road, Karachi, Karachi City, \\ Sindh 74800, Pakistan (e-mail: pasha.hamdan@gmail.com).
}

\begin{abstract}
Keywords

- atypia of undetermined significance

- thyroid nodule

- bethesda

- fine-needle aspiration

Introduction Atypia of undetermined significance (AUS) or follicular lesion of undetermined significance (FLUS) is one of the six diagnostic categories of the Bethesda System for Reporting Thyroid Cytopathology. The prevalence of malignancy among Bethesda category III cytology is variable, ranging from $5 \%$ to $37 \%$ in the literature.

Objective To determine the rate of malignancy in thyroid nodules reported as Bethesda category III.

Methods A total of 495 patients underwent surgical intervention for thyroid nodules from January 2015 to December 2017. The present study included 81 cases reported as Bethesda category III, and their medical records were reviewed.

Results Out of 495 fine-needle aspiration cytology samples, 81 (16.4\%) samples were labeled as AUS/FLUS. Among these 81 patients, the mean age was 43.0 years ( \pm 13.9 ), with only $11(14 \%)$ patients older than 55 years of age. Most of our patients were female ( $n=69 ; 85.2 \%$ ), and the rest were male. The rate of malignancy based on the final histology was of $33.3 \%(n=27)$. The majority were 17 cases $(21 \%)$ of papillary carcinoma, followed by follicular carcinoma $(n=6)(7.4 \%)$.

Conclusion The risk of malignancy can be higher than it is commonly believed, and guidelines should be based on the data from the institutions themselves for a better assessment of the outcomes.
\end{abstract}

\section{Introduction}

The global incidence of thyroid cancer is rapidly increasing largely due to incidental thyroid nodules being found on ultrasonography. Nodules have been reported in 50\% of patients aged 50 years, with a low overall malignancy risk of $5 \%$ to $7 \%{ }^{1,2}$ The most commonly employed preoperative diagnostic tool is fine-needle aspiration cytology (FNAC) for cancer risk stratification. ${ }^{1-3}$ It is not only a reliable screening test, but also a reliable and cost-effective method for the differential diagnosis of a thyroid nodule, and it reduces the rate of unnecessary thyroidectomies. ${ }^{1}$

The Bethesda System for Reporting Thyroid Cytopathology (BSRTC) was introduced in 2007, and it consists of 6 tiered

received

January 6, 2019

accepted

September 7, 2019
DOI https://doi.org/

10.1055/s-0039-1698784. ISSN 1809-9777. categories ( - Table 1) to enhance and standardize the practice of thyroid cytopathology, and subsequently facilitate the better management of thyroid nodules. This has enabled a standardized system for the reporting and management of thyroid gland FNAC results. ${ }^{4}$ Each category has an implied cancer risk and subsequent recommended management guidelines.

Among its six categories, category III, or atypia of undetermined significance/follicular lesion of undetermined significance (AUS/FLUS) was introduced for cytological features that are neither definitively benign nor definitively neoplastic, and, as such, was meant to encompass a small number of lesions that were difficult to classify. This category, however, remains under heated debate due to variations in outcomes observed across multiple studies. It now includes cases with non-specific
Copyright $(2020$ by Thieme Revinter Publicações Ltda, Rio de Janeiro, Brazil
License terms

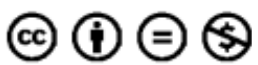


patterns affected by compromising factors such as air-drying artifacts, low cellularity or obscuring elements., ${ }^{5,6}$ Currently, the reported risk of malignancy of AUS/FLUS is between $5 \%$ and $15 \%$, but recent studies have considered a reevaluation of this probability range. ${ }^{7}$ Some have reported the potential feasibility of using thyroid ultrasound to improve predictions of malignancy of nodules assigned as undetermined cytology in the initial FNAC. ${ }^{8-11}$ A few studies reported very high malignancy rates of up $48 \%$, suggesting diagnostic lobectomy for all cases of AUS/FLUS nodules. ${ }^{12}$ Others have gone on to suggest further dividing AUS/FLUS into a two-tiered subclassification consisting of low cellularity with predominant microfollicular architecture and absence of colloid, and nuclear atypia (non-benign characteristics) attributable to the strict probability of cancer probability evaluation. ${ }^{13-15}$ Moreover, genetic studies have played their role in predicting cancer risks in such nodules, making some authors suggest their routine use. ${ }^{16}$

Our study focuses on the diagnostic distribution of Bethesda-III nodules in our institution, and we analyzed the outcomes of AUS/FLUS cases comparing them with reports in the literature. The aim of the study was to determine the rate of malignancy in thyroid nodules reported as Bethesda category III.

\section{Materials and Methods}

The present study was reviewed and approved by the ethical review committee of a tertiary healthcare center. Due to the observational design of the study, consent from patients was not needed. The data was obtained from the retrospective review of patient medical records from January 2015 to December 2017. The data collected included: patient age and gender, FNAC result, surgical intervention performed, and final histopathology diagnosis.

A total of 495 patients underwent surgical intervention for thyroid nodule, and 81 patients who had AUS/FLUS on the FNAC were recruited for inclusion in the study. Patients whose FNAC results were other than AUS/FLUS, those who had history of any prior surgical intervention for the thyroid, and those who did not underwent surgical intervention were excluded.

The data analysis was performed using the Statistical Package for the Social Sciences (SPSS, IBM Corp., Armonk, NY, US) software, version 23. The FNAC result was compared with the final histopathology report in patients who had AUS/FLUS on the initial cytology, and the frequency of benign nodules and malignancies was observed to calculate the risk.

\section{Results}

Over the period of two years, preoperative FNAC was performed in 495 patients who underwent thyroid surgery. Out of these 495 FNAC samples, 81 (16.4\%) were labeled as having AUS/FLUS ( - Table 1).

Amongst these 81 patients, the mean age was 43.0 years ( \pm 13.9 ), with only 11 (14\%) patients older than 55 years of age. Most patients were female $(n=69 ; 85.2 \%)$, and the rest were male. A total of $39(48.1 \%)$ patients underwent total
Table 1 Distribution of the cytological interpretation of thyroid fine-needle aspiration

\begin{tabular}{|l|l|l|}
\hline Bethesda Category & N & \% \\
\hline Nondiagnostic/Unsatisfactory (I) & 44 & 8.9 \\
\hline Benign (II) & 275 & 55.6 \\
\hline AUS/FLUS (III) & 81 & 16.4 \\
\hline FN/SFN (IV) & 32 & 6.5 \\
\hline Suspicious for malignancy (V) & 46 & 9.3 \\
\hline Malignant (VI) & 15 & 3.0 \\
\hline Total & 495 & 100 \\
\hline
\end{tabular}

Abbreviations: AUS, atypia of undetermined significance; FLUS, follicular lesion of undetermined significance; FN, follicular neoplasm; SFN, suspicious for follicular neoplasm.

thyroidectomy, whereas the remaining 42 (51.9\%) underwent thyroid lobectomy. Intraoperative frozen sections (FSs) of the lobectomy specimens were not collected from any of the patients. On the final histopathology, 27 (33.3\%) cases turned out to be malignant, and most ( $n=17$ [21\%]) were of papillary carcinoma, followed by follicular carcinoma $(n=6$ [7.4\%]) (-Fig. 1). There were 11 cases of classic variants of papillary carcinoma, 3 of microcarcinomas and 3 of follicular variants of papillary carcinoma.

Out of these 27 malignant cases, 8 patients initially underwent lobectomy and subsequently underwent completion thyroidectomy. Only two of them had papillary carcinoma on the contralateral lobe as well.

\section{Discussion}

Since the introduction of the BSRTC, the Bethesda-III category has been increasingly used to classify many undetermined nodules. ${ }^{17}$ The initial risk of malignancy suggested by the BSRTC ranged from $5 \%$ to $15 \%$. However, many later studies reported higher percentages of malignancies in the excised thyroid specimens. The actual incidence of malignancy for this Bethesda category is difficult to determine because many cases undergo repeat FNACs or observation with no histological confirmation of the diagnosis. These debates result in varied management options, ranging from serial ultrasounds and repeat aspirations to thyroidectomies. Many clinicians use ultrasonographic aid with Bethesda classification to determine the risk of malignancy. ${ }^{18}$ Stratifications like the thyroid imaging reporting and data system (TI-RADS) are used to suggest surgical intervention for Bethesda-III nodules when there are suspicious ultrasonographic findings and serial ultrasounds for those without. ${ }^{19}$

There is varied risk of malignancy reported in the BethesdaIII category: it ranges from $12 \%$ to $69 \%$ in the resected specimens. ${ }^{20-23}$ This wide variation could be partly explained due to interobserver variability both at the time of obtaining the specimen and during the cytological interpretation. Moreover, the prevalence of malignancy in the population could influence the percentages of malignancy in the resected specimens. However, eliminating the AUS/FLUS category decreases the 


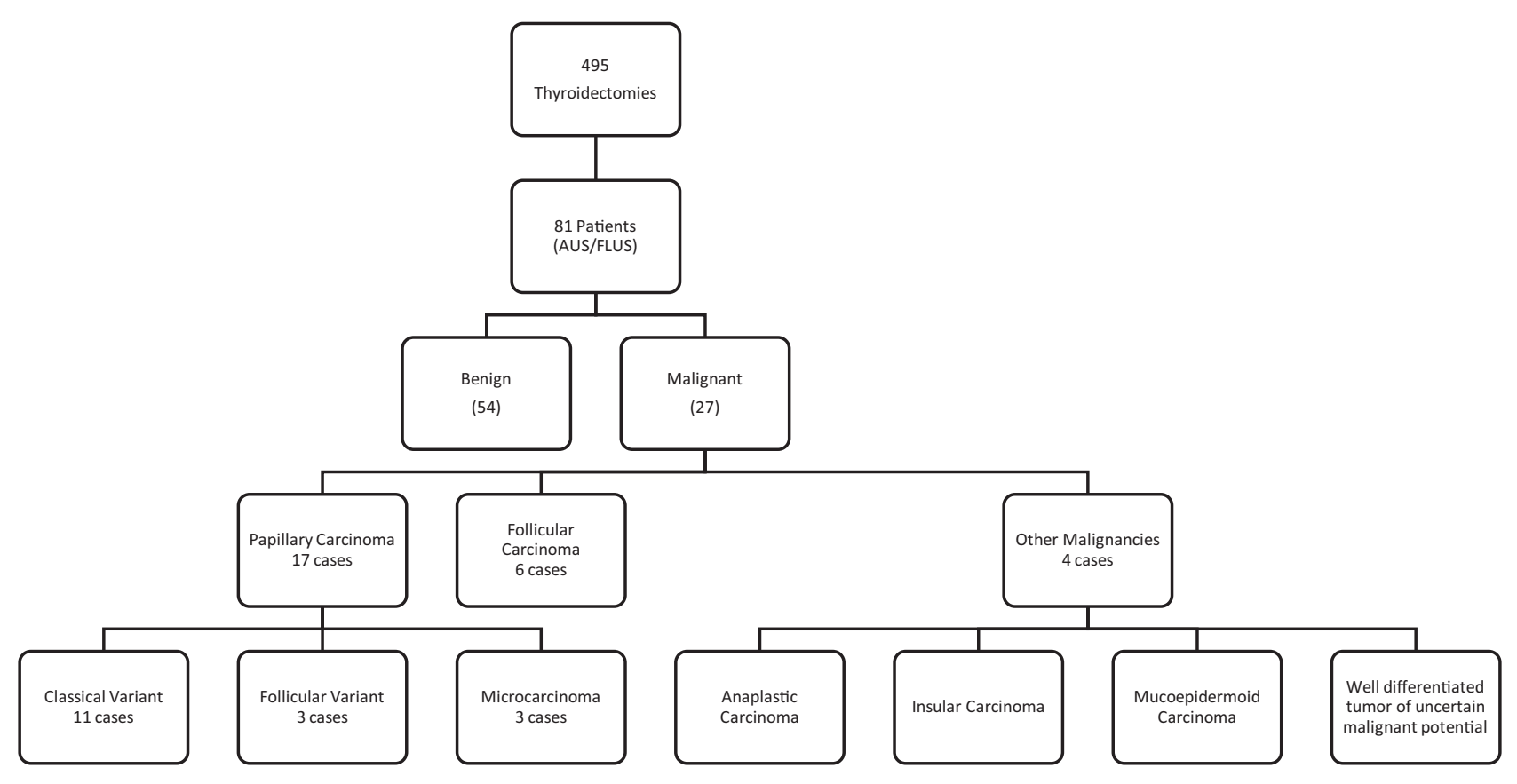

Fig. 1 Histological outcomes.

FNAC sensitivity and increases the rates of false negative and false positive results. ${ }^{24}$ Therefore, it has been suggested that institution-specific and local data should guide the subsequent management of indeterminate nodules. ${ }^{25,26}$

About 7\% of all FNAC results should be interpreted as AUS/ FLUS, but this rate has varied between $0.8 \%$ and $27 \%{ }^{2,27}$ At our center, nearly $17 \%$ of all FNACs were reported as Bethesda III. This rate might be because of the lower frequency of definitive FNAC results like categories V and VI. The overall malignancy risk was found to be higher than what has been previously suggested. One third of all AUS/FLUS nodules harbored malignancy. This can be possibly due to selection bias in a tertiary referral center like ours. None of the nodules were subjected to a repeat FNAC in our cohort to avoid any confounding results. At present, other possible investigative tools like molecular testing are not available at our center.

In our series, 27 out of 81 (33.3\%) specimens were found to be malignant. The most common malignancy was papillary carcinoma, which was found in 17 patients. Among these, 11(13.6\%) had a classic variant of papillary carcinoma. The follicular variant and microcarcinomas are difficult to be diagnosed using only the FNAC. Three cases of each of these were diagnosed in our cohort on final histology. there were 6 cases of follicular carcinoma, and 4 patients were diagnosed with rare tumors, namely insular carcinoma, anaplastic carcinoma, mucoepidermoid carcinoma and well-differentiated thyroid tumor of uncertain malignant potential.

The most common false positive results were of benign follicular adenomas, followed by thyroiditis and cysts.

We must highlight that we only reviewed cases submitted to surgical intervention. The decision to perform surgery could have been due to the clinical symptoms or worrisome radiologic findings. This would yield a malignancy risk closer to the upper bound estimate which might be a slight overestimation of the actual risk. However, according to the BSRTC, surgical interventions are adequate beyond a risk of $15 \%$ and in our setting even the lower bound estimates might still be significant for malignancy. The high malignancy rate in our practice supports the performance of thyroidectomy in patients with AUS. However, there were 22 cases submitted to total thyroidectomy based on the FNAC, but that were later found to have benign pathologies. These could have been adequately addressed with a lobectomy.

Since its advent, FNAC became a routine practice for thyroid nodule assessment, and the role of intraoperative FSs has been debated. Few authors advocate the use of FSs because of the very low false positive rates and the high specificity, of up to $90 \%{ }^{28-30}$ However, several recent series report very low sensitivities, ranging from $22 \%$ to $51 \%{ }^{31,32}$ In a recent review, Najah and Tresallet ${ }^{33}$ concluded that FSs contributed little to the diagnosis of undetermined thyroid nodules due to their low sensitivity and high false negative rates. They suggested that tumor capsular invasion, which is the hallmark to diagnose malignancy, could not be evaluated on FSs, and was only possible on permanent sections. In fact, FSs jeopardize the detection of capsular invasion because of the fragmentation of the specimen during the process. ${ }^{33}$ At our institution, FSs were never performed to augment the diagnosis of cases of Bethesda III on FNAC.

Papillary carcinoma followed by follicular carcinoma were also the two most common histological outcomes for cases of Bethesda III by other authors. ${ }^{12,34,35}$ In a recent meta-analysis, ${ }^{36}$ significant heterogeneity was found among studies with an overall malignancy rate of $27 \%$ for AUS/FLUS on FNAC. The cases classified as AUS/FLUS on FNAC had a malignancy rate much higher than that reported according to the BSRTC guidelines, whereas the follicular nodules or suspicion of follicular nodules on FNAC had a malignancy rate that was in line with the BSRTC recommendations. ${ }^{36}$ Cibas and Ali revised the usual management of the AUS/FLUS category through repeat FNAC, 
molecular testing, or lobectomy, and implied that the risk of malignancy was between $10 \%$ and $30 \%$ based on a metaanalysis of the literature published after $2007 .^{37}$

The analysis of the correlation of cytological and histological data can aid institutions and individuals enhance the criteria for diagnosis and subsequent management. However, it is important to perform the cytological-histological correlation with the understanding that the data are an overestimation of the risk of malignancy for cases of AUS/FLUS. In our setting, lobectomy seemed to be an adequate intervention for a diagnosis of AUS/FLUS.

\section{Conclusion}

We conclude that malignancy risks can be higher in some settings compared with customary beliefs. We recommend that a Bethesda-III FNAC result warrants a lobectomy for definitive histological diagnosis. However, a total thyroidectomy should not be performed based on isolated reports of Bethesda III on the cytology.

\section{Presentation}

The abstract was presented at 10th International Academic Conference in Otology, Rhinology and Laryngology (ORLIAC 2018), which was held from March 1st to 3rd, 2018 at Makati, the Philippines.

\section{Conflict of Interests}

The authors have none to disclose.

\section{References}

1 Cooper DS, Doherty GM, Haugen BR, et al; American Thyroid Association (ATA) Guidelines Taskforce on Thyroid Nodules and Differentiated Thyroid Cancer. Revised American Thyroid Association management guidelines for patients with thyroid nodules and differentiated thyroid cancer. Thyroid 2009;19(11):1167-1214

2 Cibas ES, Ali SZ; NCI Thyroid FNA State of the Science Conference. The Bethesda System For Reporting Thyroid Cytopathology. Am J Clin Pathol 2009;132(05):658-665

3 Cross PA, Poller D. The Bethesda thyroid terminology and progress towards international agreement on thyroid FNA cytology reporting. Cytopathology 2010;21(02):71-74

4 Crippa S, Mazzucchelli L, Cibas ES, Ali SZ. The Bethesda System for reporting thyroid fine-needle aspiration specimens. Am J Clin Pathol 2010;134(02):343-344, author reply 345

5 Ohori NP, Schoedel KE. Variability in the atypia of undetermined significance/follicular lesion of undetermined significance diagnosis in the Bethesda System for Reporting Thyroid Cytopathology: sources and recommendations. Acta Cytol 2011;55(06):492-498

6 Song JY, Chu YC, Kim L, Park IS, Han JY, Kim JM. Reclassifying formerly indeterminate thyroid FNAs using the Bethesda system reduces the number of inconclusive cases. Acta Cytol 2012;56 (02):122-129

7 Seagrove-Guffey MA, Hatic H, Peng H, Bates KC, Odugbesan AO. Malignancy rate of atypia of undetermined significance/follicular lesion of undetermined significance in thyroid nodules undergoing FNA in a suburban endocrinology practice: A retrospective cohort analysis. Cancer Cytopathol 2018;126(10):881-888

8 Méndez W, Rodgers SE, Lew JI, Montano R, Solórzano CC. Role of surgeon-performed ultrasound in predicting malignancy in patients with indeterminate thyroid nodules. Ann Surg Oncol 2008;15(09):2487-2492
9 Horne MJ, Chhieng DC, Theoharis C, et al. Thyroid follicular lesion of undetermined significance: Evaluation of the risk of malignancy using the two-tier sub-classification. Diagn Cytopathol 2012; 40(05):410-415

10 Akın S. Atypia of Undetermined Significance on Thyroid Fine Needle Aspiration Cytology: Pathological Evaluation and Risk Factors for Malignancy. South Clin Istanb Eurasia [Internet]. 2017 [cited 2019 Jul 30]; Available from: http://scie.online/jvi. aspx? un $=\mathrm{KEAH}-54926$

11 Hong S-H, Lee H, Cho M-S, Lee JE, Sung Y-A, Hong YS. Malignancy Risk and Related Factors of Atypia of Undetermined Significance/ Follicular Lesion of Undetermined Significance in Thyroid Fine Needle Aspiration. Int J Endocrinol 2018;2018:4521984

12 López Vázquez Y, Penín Álvarez M, San Miguel Fraile P, Barragáns Pérez M. Riesgo de malignidad de los nódulos tiroideos con atipia de significado incierto. Endocrinol Nutr 2015;62(10):507-510

13 Luu MH, Fischer AH, Stockl TJ, Pisharodi L, Owens CL. Atypical follicular cells with equivocal features of papillary thyroid carcinoma is not a low-risk cytologic diagnosis. Acta Cytol 2011;55 (06):526-530

$14 \mathrm{Kim}$ SJ, Roh J, Baek JH, et al. Risk of malignancy according to subclassification of the atypia of undetermined significance or follicular lesion of undetermined significance (AUS/FLUS) category in the Bethesda system for reporting thyroid cytopathology. Cytopathology 2017;28(01):65-73

15 Eisa N, Khan A, Akhter M, et al. Both Ultrasound Features and Nuclear Atypia are Associated with Malignancy in Thyroid Nodules with Atypia of Undetermined Significance. Ann Surg Oncol 2018;25(13):3913-3918

16 Seo JW, Jang AL, Suh SH, Park HS, Kang MK, Hong JC. Atypia of undetermined significance on thyroid fine needle aspiration risk factors for malignancy. Clin Otolaryngol 2017;42(02): 234-238

17 Sullivan PS, Hirschowitz SL, Fung PC, Apple SK. The impact of atypia/ follicular lesion of undetermined significance and repeat fineneedle aspiration: 5 years before and after implementation of the Bethesda System. Cancer Cytopathol 2014;122(12):866-872

18 Gweon HM, Son EJ, Youk JH, Kim J-A. Thyroid nodules with Bethesda system III cytology: can ultrasonography guide the next step? Ann Surg Oncol 2013;20(09):3083-3088

19 Maia FFR, Matos PS, Pavin EJ, Zantut-Wittmann DE. Thyroid imaging reporting and data system score combined with Bethesda system for malignancy risk stratification in thyroid nodules with indeterminate results on cytology. Clin Endocrinol (Oxf) 2015;82(03):439-444

20 Bongiovanni M, Piana S, Spitale A, Valli R, Carlinfante G, Gardini G. Comparison of the diagnostic accuracy of thyroid fine-needle aspiration in follicular-patterned lesions using a 5-tiered and a 6-tiered diagnostic system: a double-blind study of 140 cases with histological confirmation. Diagn Cytopathol 2014;42(09): 744-750

21 Raparia K, Min SK, Mody DR, Anton R, Amrikachi M. Clinical outcomes for "suspicious" category in thyroid fine-needle aspiration biopsy: Patient's sex and nodule size are possible predictors of malignancy. Arch Pathol Lab Med 2009;133(05):787-790

22 Harvey AM, Mody DR, Amrikachi M. Thyroid fine-needle aspiration reporting rates and outcomes before and after Bethesda implementation within a combined academic and community hospital system. Arch Pathol Lab Med 2013;137(11):1664-1668

23 Rabaglia JL, Kabbani W, Wallace L, et al. Effect of the Bethesda system for reporting thyroid cytopathology on thyroidectomy rates and malignancy risk in cytologically indeterminate lesions. Surgery 2010;148(06):1267-1272, discussion 1272-1273

24 Shi Y, Ding X, Klein M, et al. Thyroid fine-needle aspiration with atypia of undetermined significance: a necessary or optional category? Cancer 2009;117(05):298-304

25 Broome JT, Solorzano CC. The impact of atypia/follicular lesion of undetermined significance on the rate of malignancy in thyroid fine- 
needle aspiration: evaluation of the Bethesda System for Reporting Thyroid Cytopathology. Surgery 2011;150(06):1234-1241

26 Bernstein JM, Shah M, MacMillan C, Freeman JL. Institutionspecific risk of papillary thyroid carcinoma in atypia/follicular lesion of undetermined significance. Head Neck 2016;38 (Suppl 1):E1210-E1215

27 Kholová I, Ludvíková M. Thyroid atypia of undetermined significance or follicular lesion of undetermined significance: an indispensable Bethesda 2010 diagnostic category or waste garbage? Acta Cytol 2014;58(04):319-329

28 Kennedy JM, Robinson RA. Thyroid Frozen Sections in Patients With Preoperative FNAs: Review of Surgeons' Preoperative Rationale, Intraoperative Decisions, and Final Outcome. Am J Clin Pathol 2016;145(05):660-665

29 Kahmke R, Lee WT, Puscas L, et al. Utility of Intraoperative Frozen Sections during Thyroid Surgery. Int J Otolaryngol 2013;2013:496138

30 Cohen MA, Patel KR, Gromis J, et al. Retrospective evaluation of frozen section use for thyroid nodules with a prior fine needle aspiration diagnosis of Bethesda II-VI: The Weill Cornell Medical College experience. World J Otorhinolaryngol Head Neck Surg 2015;1(01):5-10

31 Berg RW, Yen TW, Evans DB, et al. Analysis of an institutional protocol for thyroid lobectomy: Utility of routine intraoperative frozen section and expedited (overnight) pathology. Surgery 2016;159(02):512-517

32 Mayooran N, Waters PS, Kaim Khani TY, Kerin MJ, Quill D. FNAC and frozen section correlations with definitive histology in thyroid diseases. Eur Arch Otorhinolaryngol. 2016;273(08):2181-2184

33 Najah $\mathrm{H}$, Tresallet $\mathrm{C}$. Role of frozen section in the surgical management of indeterminate thyroid nodules. Gland Surg [Internet]. 2019 Apr 19 [cited 2019 Jul 30];0(0). Available from: http://gs.amegroups.com/article/view/25191

34 Ho AS, Sarti EE, Jain KS, et al. Malignancy rate in thyroid nodules classified as Bethesda category III (AUS/FLUS). Thyroid 2014;24 (05):832-839

35 Jan I-S, Lee Y-T, Wang C-M, et al. The surgery and repeat aspiration outcomes of the atypia of undetermined significance/follicular lesion of undetermined significance category in The Bethesda System for Reporting Thyroid Cytopathology. Asian J Surg 2019; 42(01):144-147

36 Straccia P, Rossi ED, Bizzarro T, et al. A meta-analytic review of the Bethesda System for Reporting Thyroid Cytopathology: Has the rate of malignancy in indeterminate lesions been underestimated? Cancer Cytopathol 2015;123(12):713-722

37 Cibas ES, Ali SZ. The 2017 Bethesda System for Reporting Thyroid Cytopathology. Thyroid 2017;27(11):1341-1346 